\title{
A (re)construção do espaço urbano de Aparecida de Goiânia
}

\author{
Deusa Maria Rodrigues Boaventura \\ Departamento de Arquitetura da Pontifícia Universidade Católica de Goiás (PUC Goiás) \\ Lorena Sulino Assunção \\ Mestranda do Programa de Pós-Graduação em Desenvolvimento e Planejamento Territorial da Pontifícia \\ Universidade Católica de Goiás (PUC Goiás)
}

Recebido: 24/06/2013 Versão revisada (entregue): 29/11/2013 Aprovado: 03/12/2013

\section{Resumo}

Equalizar a gestão das questões de ordem política, social, ambiental, econômica e territorial com a participação comunitária é um grande desafio para a administração pública. O Plano Diretor Municipal e o Planejamento Estratégico Municipal são importantes instrumentos de Planejamento Urbano que podem contribuir para a atuação dos gestores municipais. Se o Estatuto da Cidade confere ao Plano Diretor determinações metodológicas e operacionais de elaboração, a maior flexibilidade e liberdade do Planejamento Estratégico permite que este contribua com maiores oportunidades de adequação às necessidades urbanas para as quais se propõe. Neste artigo analisa-se o caso de Aparecida de Goiânia, município do estado de Goiás, cujo Plano Diretor foi implantado, simultaneamente, com um Planejamento Estratégico que se transformou em lei. Contudo, uma lei sem monitoramento e carente de fiscalização.

Palavras-chave | Aparecida de Goiânia; gestão municipal; planejamento estratégico; Plano Diretor; política urbana.

Código JEL | O18; O21; H70.

\section{THE RECONSTRUCTION OF THE URBAN SPACE OF APARECIDA DE GOIÂNIA}

\begin{abstract}
Equalizing the management of political, social, environmental, economic and territorial issues with community participation is undoubtedly one of the greatest challenges for the public administration. The City Master Plan and the Local Strategic Planning are important urban planning instruments, which may contribute to the performance of municipal managers. If the City Statute confers methodological and operational determinations for the preparation of the City Master Plan, a greater flexibility and freedom of the Local Strategic Planning allows it to contribute to better meet the urban needs for which it is intended. In this article we analyze the case of Aparecida de Goiânia (a municipality of the Brazilian State of Goiás), whose City Master
\end{abstract}


Plan was implemented simultaneously with the Local Strategic Planning, which later became law. However, it is a law neither monitored nor supervised.

Keywords | Aparecida de Goiânia; city master plan; local strategic planning; municipal management; urban policy.

JEL-Code | O18; O21; H70.

\section{LA (RE)CONSTRUCCIÓN DEL ESPACIO URBANO DE APARECIDA DE GOIÂNIA}

\section{Resumen}

Ecualizar la gestión de los asuntos de orden política, social, ambiental, económica y territorial con la participación de la comunidad es un grande desafío para la administración pública. El Plan Director Municipal y la Planificación Estratégica Municipal son importantes instrumentos de planificación urbana que pueden contribuir a la actuación de los gestores municipales. Si el Estatuto de la Ciudad le da al Plan Director determinaciones metodológicas y operativas de elaboración, la mayor flexibilidad y libertad de la planificación estratégica permite que éste contribuya con mayores oportunidades de adecuación a la necesidad urbana que se propone. En este artículo se analiza el caso de Aparecida de Goiânia, municipio del Estado de Goiás, cuyo Plan Director fue implantado de forma simultánea con una planificación estratégica que se convirtió en ley. Sin embargo, una ley sin monitoreo y carente de supervisión.

Palabras-clave | Aparecida de Goiânia; gestión municipal; Plan Director; planificación estratégica; política urbana.

Código JEL | O18; O21; H70.

\section{Introdução}

Entende-se que, mesmo com leis pouco aplicáveis, como são as brasileiras, planejar a cidade é fundamental para o início de uma gestão municipal eficiente. Num bom planejamento, ações como o bem-estar dos munícipes, as especificidades do município - que devem ser observadas de forma relevante -, as obrigatoriedades de uso e ocupação do solo, entre outros aspectos de ordenação territorial, norteiam de forma generalizada, porém única, os caminhos que serão traçados pela cidade. Tendo em vista que o ordenamento do território urbano está relacionado ao desenvolvimento das funções sociais da cidade, as leis urbanísticas brasileiras pouco se têm ocupado com a qualidade de vida da sociedade urbana, haja visto os interesses do mercado na era do empresariamento urbano.

O planejamento urbano includente, segundo Maricato (2003), indica dois caminhos: urbanizar e legalizar. Os processos de urbanização têm se tornado cada dia mais frequentes no país e sua legalização torna completas as condições sociais dos cidadãos. Dentro dos inúmeros instrumentos do planejamento urbano capazes de construir e reconstruir o espaço urbano das cidades, destacam-se, neste 
artigo, o Plano Diretor Municipal - PDM e o Planejamento Estratégico Municipal - PEM aplicados a Aparecida de Goiânia, Goiás.

A cidade de Aparecida de Goiânia desenvolveu-se como uma "periferia" de Goiânia que, por falta de gerência e impulsionada por forte poder especulativo imobiliário, permitiu o surgimento de loteamentos espraiados num território sem infraestrutura básica para a fixação da população mais pobre, tanto da capital como do próprio município. Com uma malha urbana dispersa, Aparecida de Goiânia possui elevados custos de infraestrutura, o que acaba por dificultar o acesso da população aos serviços urbanos (transporte coletivo, saneamento, drenagem, saúde, educação, pavimentação etc.) e por segregar uma população marginalizada de oportunidades de emprego e profissionalização, tornando-a vulnerável à violência e à discriminação social.

As teorias do planejamento estratégico municipal de Aparecida de Goiânia apresentam-se de forma preliminar e sutil, assemelhando-se mais a uma política estratégica. Essa política estratégica do município foi implementada a partir do Plano Diretor Participativo de 2001 e com a Lei de Política de Ordenação para o Crescimento e Desenvolvimento Estratégico do Município de Aparecida de Goiânia - POCDE, que puderam contribuir para a reorganização espacial da cidade.

\section{Planejamento urbano}

Após a eclosão da II Guerra Mundial (1939-1945), o mundo viveu a era da intervenção estatal, com a saída para a crise econômica efetivada através dos princípios keynesianos fundamentados na afirmação do Estado como agente indispensável de controle da economia - o Estado Intervencionista. As ideias socioeconômicas de Keynes foram adotadas pelas principais potências econômicas do Ocidente durante as décadas de 1950 e 1960 e o seu sucesso foi de tal monta que quase todos os governos capitalistas adotaram suas recomendações (ARRETCHE, 1995).

Os instrumentos e/ou conjunto de ações regulados pelo Estado passaram a justificar-se como tentativas de adequar demandas sociais às necessidades da população. Este é, sem dúvida, o dado inovador e a maior contribuição de Keynes no fundamento econômico e social do Estado de Bem-Estar ou, como também é conhecido em países da Europa, Welfare State ${ }^{1}$.

\footnotetext{
${ }^{1}$ Os termos servem basicamente para designar o Estado assistencial que garante padrões mínimos de saúde, habitação, emprego, alimentação, segurança e educação a todos os cidadãos. Para Keynes, porém, essa intervenção estatal deveria ser uma interferência provisória.
} 
O Estado se substitui aos mecanismos espontâneos do mercado, para assegurar o equilíbrio econômico e o crescimento, mas sem eliminar a sociedade civil em favor de um sistema coletivista. Keynes não acredita no socialismo de Estado, assim como se declara contrário ao princípio das nacionalizações: o Estado não deve assumir a propriedade dos meios de produção. Se o poder público deve intervir em apoio à sociedade civil, sua gestão deve ser apenas temporária (DROUIN, 2008, p. 128).

O Estado de Bem-Estar foi amplamente aplicado principalmente após o surgimento do Informe Beveridge. O Welfare State derivado do Informe foi constituído de maneira diferente do que ocorria anteriormente, já que não era uma simples questão de seguridade social visando os interesses dos "necessitados", mas envolvia a sociedade como um todo (CARDOSO, [2010?]). Tratava-se de uma nova forma de assistência social que saía da esfera privada e se tornava objeto de política pública. No Brasil, o Informe Beveridge influenciou a elaboração da Constituição de 1988.

Segundo Gramsci (1971 apud GRUPPI, 1980), o Estado tem um caráter contraditório: é um instrumento de classe, porém é também um elemento autônomo e regulador dessa classe. Assim, o planejamento torna-se um mecanismo institucional que permite ao Estado impor-se como entidade detentora do poder mediante mecanismos de distribuição de recursos e incentivos ao consumo, definidos pelo próprio Estado. $\mathrm{Na}$ verdade, o Estado está mais intimamente vinculado aos interesses do mercado ao invés de se preocupar com a promoção de um desenvolvimento econômico mais igualitário em todo o seu território. O que move o Estado são as regras do mercado e, assim, o planejamento se molda segundo as necessidades do "grande capital" e os interesses políticos de uma minoria. O ideal do planejamento como meio para um desenvolvimento social e econômico mais justo é o discurso repassado à sociedade, mas, na verdade, o planejamento é feito de "cima para baixo" para o fortalecimento das classes dominantes.

Segundo Villaça (2005), entre 1875 e 1906, os planos urbanos referiam-se basicamente ao melhoramento e embelezamento das cidades. Tais planos persistiram até os anos de 1930 e 1940, incorporando, nesse período, a preocupação com a infraestrutura urbana, principalmente a referente ao saneamento. A partir de então, a "eficiência, a ciência e a técnica começaram a substituir os conceitos de melhoramento e embelezamento." (ARANTES; VAINER; MARICATO, 2012, p. 138).

Da influência keynesiana, esse "planejamento incorporou o Estado como a figura central para assegurar o equilíbrio econômico e social” (ARANTES; VAINER; MARICATO, 2012, p. 126), trazendo, historicamente, ações relativas às questões econômicas. Contudo, o plano econômico de um país é também um plano 
político e influencia no caminho por onde o desenvolvimento do país deve passar. Desse modo, no fim dos anos 1950, a procura do poder público por planejadores foi altamente fomentada, fundamentada na necessidade de planos econômicos de reconstrução e reestruturação. O planejamento urbano passou, então, a assumir posição de destaque no processo de desenvolvimento, garantindo sua racionalização e implementação de objetivos (DEL RIO, 1990).

No Brasil, a partir da segunda metade do século XX, durante o segundo governo Vargas (1951-1954), inicia-se um período de intensa urbanização e industrialização, com o empobrecimento das áreas rurais e o crescimento da população marginalizada nas cidades. Houve a consolidação das bases institucionais e infraestruturais para o avanço industrial subsequente que o país passaria com o governo de Kubitschek (1956-1961). Essa industrialização e a produção no campo, marcada pela concentração fundiária e a exploração do trabalhador rural, ocasionariam a forte migração dos trabalhadores rurais para os centros urbanos (RODRIGUES, 2005).

Entre 1960 e 1970, os países capitalistas do Primeiro Mundo, nos quais as teorias do planejamento urbano vinham sendo aplicadas, já verificavam alguns entraves no planejamento como instrumento de política urbana. De outro lado, também nesse período (década de 1970), o planejamento urbano começou a modificar seu caminho: ao invés de regular o crescimento urbano, propôs-se a encorajar tal crescimento a fim de produzir riquezas urbanas, atrair o comércio e aumentar o valor dos imóveis (ARANTES; VAINER; MARICATO, 2012).

Foi também no final dos anos 60 e início dos 70 que se veriam expostos os resultados e limitações dos processos e práticas do Planejamento Urbano. Nos países de Primeiro Mundo, onde a institucionalização destes processos está aliada a economias capitalistas avançadas, poderíamos identificar duas razões principais por trás destas dificuldades do Planejamento enquanto meio de implementar ambientes satisfatórios, tanto social quanto economicamente. A primeira razão estaria no plano político e, consequentemente, nos próprios objetivos do Planejamento. [...] A segunda razão das dificuldades encontradas pelo Planejamento Urbano está no excessivo tecnocracismo que permeava suas teorias e métodos de análise e implantação (DEL RIO, 1990, p. 43-44).

O Brasil vivia, desde o final da década de 1960 e início dos anos de 1970, uma das mais aceleradas urbanizações do mundo - com mais pessoas morando em áreas urbanas que rurais (segundo estimativas da ONU, esse episódio aconteceu mundialmente a partir do ano de 2007). A região Centro-Oeste, que, até 1960, era a de menor urbanização do país, saltaria para a segunda posição no ranking nacional. 
O Centro-Oeste [...] apresenta-se como extremamente receptivo aos novos fenômenos da urbanização, já que era praticamente virgem, não possuindo infraestrutura de monta, nem outros investimentos fixos vindos do passado e que pudessem dificultar a implantação de inovações. Pôde, assim, receber uma infraestrutura nova, totalmente a serviço de uma economia moderna, já que em seu território eram praticamente ausentes as marcas dos precedentes sistemas técnicos. Desse modo, aí o novo vai dar-se com maior velocidade e rentabilidade. E é por isso que o Centro-Oeste conhece uma taxa extremamente alta de urbanização, podendo nele se instalar, de uma só vez, toda a materialidade contemporânea indispensável a uma economia exigente de movimento (SANTOS, 1993, p. 61).

Esse aumento da população urbana em relação à rural aconteceu com a modernização do território nacional, mas sem a implementação de políticas públicas adequadas para a inserção do segmento populacional rural nas cidades (SANTOS, 1993; MARICATO, 2003). Os planos urbanos desse período foram altamente fomentados, dado o regime militar que regia o país e esse sistema de novos planos e um planejamento positivista, com o intuito de reordenar o caos urbano, persistiram até os anos 1980. Com a Constituição de 1988, o plano diretor municipal foi restabelecido e tomou prestígio nas cidades.

Com o Estado provedor dos bens e serviços, a "máquina emperrou" e o Estado brasileiro não conseguiu realizar suas funções, passando a adotar o ideário neoliberal. Apropriando-se desse ideário, o Estado se desligou de algumas das suas funções, principalmente na área social, o que justificou as privatizações e terceirizações, que não preservaram os direitos sociais - e, em alguns casos, civis da sociedade. O Estado passou a ser um gestor da administração pública. Com a crescente dos negócios e das trocas, ele viu a necessidade de uma nova regulação, a qual visava garantir uma estabilidade nas relações. Tem-se, então, o Estado Regulador, o "Estado territorial, o território nacional, o Estado nacional, que passam a reger o dinheiro.” (SANTOS, 1999, p. 9).

Logo, a urbanização brasileira, que teve seu marco inicial na década de 1950 com o fim da economia colonial e o grande impulso industrial, foi a própria impulsionadora do desequilibrio entre a oferta e a demanda de trabalho, rebaixando os salários e não permitindo que a população tivesse acesso aos frutos da industrialização e da urbanização.

Portanto, não é possível nem desejável, mas obrigatório que os instrumentos políticos e jurídicos do planejamento urbano aplicados em qualquer esfera de governo (municipal, estadual ou federal) provoquem e adequem as mudanças físicas constantes do tecido urbano e rural, tendo como pressuposto estabelecer meios que direcionem e controlem, também, a especulação imobiliária, que tem assumido, em prol do capital, um importante papel na expansão urbana desordenada. 
O desenvolvimento urbano, principalmente nos moldes observados na maioria das cidades brasileiras, possibilitou a especulação e a valorização imobiliárias, indo contra os conceitos de que, na cidade, os padrões urbanísticos devem se adequar à regulação social. Desse modo, manteve-se a perspectiva do mercado imobiliário, que visa otimizar e maximizar os empreendimentos capitalistas em detrimento da inclusão de segmentos sociais situados fora do mercado. De outro lado, a grande variedade de planos urbanos que a legislação brasileira determina também é outro vetor para a irresponsabilidade na sua elaboração e sua inaplicabilidade.

É necessário que os municípios tenham capacidade de desenvolver planos e projetos urbanísticos voltados à realidade municipal específica, haja visto que o ente federado municipal é o responsável direto pela gestão das questões territoriais, financeiras, ambientais, administrativas, políticas e sociais do município.

Para tanto, a gestão municipal precisa ancorar-se na Constituição Federal, na Lei de Responsabilidade Fiscal, no Estatuto da Cidade, além da própria Lei Orgânica Municipal. Com esse arcabouço de leis, o município deve estabelecer seu Plano Plurianual, constituído pela Lei do Plano Plurianual (PPA), a Lei de Diretrizes Orçamentárias (LDO) e a Lei Orçamentária Anual (LOA), além do seu Plano Diretor Municipal (PDM) e do Planejamento Estratégico Municipal (PEM) (REZENDE, 2006). São esses instrumentos de planejamento e política urbana que, frequentemente, norteiam as mudanças físicas nas cidades, uma vez que visam coordenar o espaço urbano e ordenar os limites da malha urbana.

\section{Plano Diretor Municipal - PDM}

O urbanismo de origem francesa transforma-se em planejamento por influência norte-americana no final do século XIX e início do século XX, quando surgem os planos de embelezamento das cidades. No Brasil, a ideia de plano diretor iniciouse em 1930, no Rio de Janeiro, com o urbanista francês Agache, que elaborou um plano para a cidade fluminense que ficou conhecido como Plano Agache. A partir da década de 1950, a cidade começa a ser vista e entendida não somente como uma entidade física, social e política, mas principalmente como um organismo econômico. Assim, os primeiros planos diretores dessa década se baseavam nesse discurso (VILLAÇA, 2005).

Os municípios têm como responsabilidade a elaboração de seus planos diretores desde a Constituição de 1988 (BRASIL, 1988), sendo que os artigos da Constituição que tratam do planejamento urbano $\left(\mathrm{n}^{\text {os }} .182\right.$ e 183) foram regulamentados em 10 de julho de 2001 pela Lei $\mathrm{n}^{\circ}$ 10.257, conhecida como Estatuto da Cidade. 
A Constituição Federal de 1988 trouxe para o seio da sociedade brasileira, recém empossada de seus direitos democráticos, um princípio básico para a equidade urbana e a justa distribuição dos ônus e benefícios do processo de urbanização: o princípio da função social da cidade e da propriedade. [...] Além desse princípio, o texto constitucional afirmou o papel protagonista dos municípios enquanto principais atores da política de desenvolvimento e gestão urbanos e elegeu o Plano Diretor como instrumento básico da política de desenvolvimento e expansão urbana [...] Passada a criação desse marco jurídico para a política de desenvolvimento urbano, tivemos que aguardar mais treze anos para que finalmente fosse criada uma lei federal que regulamentasse os artigos constitucionais que tratam da política urbana. A Lei n. 10.257 de 10 de julho de 2001, denominada Estatuto da Cidade (SANTOS JUNIOR; MONTANDON, 2011, p. 13).

O Estatuto da Cidade tentou assegurar, mesmo em uma sociedade desigual, novas formas de sociabilidade e participação popular. Essa é, para Harvey (2012), uma das possibilidades de se superarem as energias do capital, uma vez que as ações públicas devem ser norteadas pelos princípios da inclusão social, universalização de acesso aos bens e serviços e formas de controle social e democrático.

O Estatuto da Cidade definiu a elaboração do Plano Diretor Municipal - PDM de forma participativa, com o envolvimento de técnicos, gestores municipais, legislativo, segmentos sociais diversos, enfim, os cidadãos interessados em discutir e planejar a cidade. Os planos diretores participativos ou democráticos, elaborados à luz do Estatuto da Cidade, tornaram-se instrumentos urbanísticos, cujas diretrizes, programas, projetos, estratégias e ações, organizados em mapas e leis, ordenam o uso e a ocupação da cidade e da propriedade e acabam interferindo no desenho urbano. São obrigatórios para municípios com mais de 20 mil habitantes, integrantes de regiões metropolitanas e aglomerações urbanas, os integrantes de áreas de especial interesse turístico e os inseridos em áreas de influência de empreendimentos ou atividades com significativo impacto ambiental em âmbito regional ou nacional (BRASIL, 2001).

Vários são os instrumentos previstos no Estatuto da Cidade: a regularização urbanística e fundiária; a implementação de áreas de especial interesse social; a utilização compulsória de terrenos e imóveis considerados subutilizados; a outorga onerosa e a transferência do direito de construir; a utilização mais adequada do imposto predial e territorial urbano - IPTU; as operações consorciadas, dentre outros (ROLNIK; PINHEIRO, 2005). É por meio desses instrumentos que são balizadas as variáveis de construção e concepção urbana, definidos os índices de ocupações e, principalmente, estabelecidas as ferramentas de controle das mudanças no espaço urbano, o que interfere na qualidade de vida das cidades. 
Com esses instrumentos, a gestão municipal é capaz de se apoiar e intervir no processo de planejamento e gestão urbana e territorial, garantindo o direito de todos à cidade. Entretanto, a velha crença de que tudo que interessa ao município deve ser contemplado pelo seu plano diretor fez com que ações de responsabilidade estadual ou federal, que não são da alçada municipal (como o saneamento), fossem por ele incorporadas, tornando-o mais uma lista de propostas de cumprimento não obrigado, gerando descrédito ao planejamento. Deve-se dar atenção a esse poder que o plano diretor carrega e que ilude, com seu conjunto de boas intenções, muitos estudiosos e gestores públicos.

Mas, qual seria, na verdade, a operacionalização dessa lei? Se ela traz obrigações, como os Códigos de Obras, a maior parte da população não tem condições econômicas ou culturais, sociais ou territoriais de cumpri-las - vide as favelas. Também os infratores não possuem sanções, e à própria lei faltam condições de ser aplicada e fiscalizada. Ou seja, limita-se a lei a generalidades, teorizações e boas intenções (VILLAÇA, 2005, 2012).

No entanto, os códigos de obras e de loteamentos são cumpridos (claro que com todos os percalços típicos do cumprimento da maior parte das leis no Brasil) para as casas e loteamentos das classes média e acima da média. São ignoradas para os mais pobres - para as favelas e para os milhões de moradias clandestinas que há no país. Isso mostra que a lei só vale para os mais ricos, tanto que eles, quando acham necessário, procuram mudá-la (VILLAÇA, 2012, p. 221).

Para Maricato (2003), a legislação urbanística brasileira serviu, em muitos casos, para excluir a população de pouca condição financeira de bens e serviços, locando-a nas periferias das cidades, realidade que tem contribuído para uma segregação espacial comandada pelo mercado imobiliário, que obriga essa população a conviver com a ilegalidade da terra e a precariedade das construções.

O PDM é sem dúvida um instrumento de política urbana necessário às cidades. Sendo assim, uma atenção especial deve ser dada à sua elaboração, principalmente por ter se tornado instrumento de cobiça dos agentes ${ }^{2}$ responsáveis pela produção das cidades. Nos moldes em que hoje é concebido por todo o território nacional tem-se elitizado e estado permeado de arranjos políticos que visam regular as atividades das classes dominantes, ou seja, do próprio mercado.

\footnotetext{
${ }^{2}$ De acordo com Corrêa (1995), os agentes sociais responsáveis pela produção do espaço urbano e das cidades são: i) os proprietários dos meios de produção, grandes industriais; ii) os proprietários fundiários; iii) os promotores imobiliários; iv) o Estado; e v) os grupos sociais excluídos.
} 


\section{Planejamento Estratégico Municipal - PEM (Políticas Estratégicas)}

O Planejamento Estratégico Municipal - PEM tem sua raiz na esfera privada e sua proposta é a prática de ações mais objetivas na administração pública. Entretanto, ainda não é um instrumento de política pública habitual nas gestões municipais brasileiras. Teve seu início nos anos 1980, em cidades dos Estados Unidos, que passaram a experimentar e a adaptar o planejamento estratégico às necessidades locais, especialmente após algumas mudanças na economia nacional, que forçaram os gestores públicos a procurar novas oportunidades (PFEIFFER, 2000).

Os conceitos do PEM, advindos das teorias do planejamento empresarial, quando adotados pelo poder público possibilitam ações urbanas mais focadas nas excepcionalidades de cada cidade, podendo elaborar planos de curto, médio ou longo prazo, também conhecidos como políticas estratégicas. Quando compatibilizados com os demais instrumentos do planejamento urbano, assumem "caráter integral e integrado, abordando múltiplas questões na área urbana e na área rural”, o que certamente contará para o sucesso do planejamento urbano municipal (REZENDE; ULTRAMARI, 2007, p. 259).

Entretanto, é preciso ressaltar que o planejamento estratégico não substitui, nem pode substituir, os instrumentos legais de planejamento da administração pública (PPA, LDO, LOA, PDM). Ele é complementar aos mecanismos de gestão municipal e pode melhorar o desempenho do município. Diferentemente do plano diretor, ele não é uma norma ou obrigação municipal, tanto é que a metodologia para a sua elaboração segue recomendações da literatura empresarial: diagnóstico, diretrizes, estratégias, ações e formas de controle.

Além dessas fases, está intrínseco ao planejamento estratégico o envolvimento dos atores responsáveis pelas áreas a serem desenvolvidas e o líder do projeto. Há também as determinações do período de execução do planejamento, suas metas, os recursos necessários para sua implementação e as orientações para o controle e a avaliação das ações implementadas. De acordo com Pfeiffer (2000), o planejamento estratégico é um processo permanente, cujo ambiente institucional é observado, as ações são planejadas e executadas, e os seus impactos avaliados antes do reinício de seu ciclo.

Assim, uma das principais prioridades - e também um dos maiores desafios - do PEM é não ser apenas uma forma de organização das aspirações municipais. Ele precisa trazer, prioritariamente, o que necessita ser feito para transformar as pretensões em realidade. Para isso, deve situar "como o município está" para depois estabelecer "aonde o município quer chegar". Conforme Rezende; Ultramari (2007, p. 265), “o planejamento estratégico municipal (PEM) é um processo dinâmico e interativo para a determinação dos objetivos, estratégias e ações do município”. 
O planejamento estratégico pode ser elaborado contendo vários planos/projetos e pode ser executado por mais de um plano/projeto estratégico ao mesmo tempo, dentro da instituição. Por exemplo, em uma prefeitura, a Secretaria de Habitação pode estabelecer seu plano estratégico simultaneamente ao plano da Assistência Social. Ainda podem ser elaboradas políticas estratégicas com as mesmas características do planejamento estratégico, porém em uma escala menor.

Contudo, o mais importante é que todos do poder público conheçam qual a "missão" do município para que as ações sejam coerentes e compatíveis. Deve-se ter um conhecimento pragmático do ambiente municipal para se definir o plano, porque, como todas as áreas (social, educacional, habitacional, territorial e outras) dos municípios têm problemas, a questão é estabelecer o que é ou não estratégico, "para evitar que velhos produtos recebam apenas um novo rótulo." (PFEIFFER, 2000, p. 10). Deve-se evitar que o PEM seja apenas um conjunto de descrições gerais de ações previstas ou ações enunciadas sem qualquer preocupação com "quem" vai executá-las, ou "quando", "como" ou ainda, "com que recurso".

O planejamento estratégico tem, basicamente, dois propósitos: o de direcionar as forças dentro da instituição, fazendo com que seus membros trabalhem numa mesma direção, e o de analisar as ameaças de entorno para reagir aos desafios que vierem, procurando reger a instituição, seja ela privada, pública ou entidade não governamental, para desenvolver seus processos e não ser conduzida pelas externalidades (PFEIFFER, 2000). Os conceitos tradicionais do PEM incentivam a competitividade estratégica e a busca por investimentos. Todavia, essas questões devem ser utilizadas com cautela dentro do planejamento urbano, e questões de natureza socioambiental devem ser prioritárias, principalmente quando legitimadas pela participação popular. A presença de empresas globais no território nacional provoca uma desorganização, já que suas regras visam interesses próprios e nem sempre se preocupam com o bem estar da cidade e dos seus munícipes (SANTOS, 1999).

Ao incorporar os aspectos empresariais à gestão pública - não por ser esse planejamento estratégico um caminho mais objetivo, mas porque visa, sobretudo, a lógica do dinheiro, a lógica da concorrência -, as cidades tornam-se competitivas na economia moderna. Tal competitividade é a busca por investidores, a venda de cidades. Atualmente, a promoção das cidades já não se limita aos tradicionais fins turísticos ou comerciais. As políticas estratégicas garantem a atuação em diversos setores municipais, que podem impulsionar o desenvolvimento econômico local e regional, como são os casos da promoção de eixos comerciais, de torres de comunicação e de parques industriais e tecnológicos (BORJA; FORN, 1996).

É necessário enfatizar que, quando se fala em comercialização de cidades, não é simples a verificação do que está à venda. Afinal, o que se vende tende a ser compatível com o interesse de quem compra e daí uma infinidade de atributos podem ser negociados: desde polos industriais, espaços para convenções, centros 
comerciais, arenas esportivas, bairros residenciais (elitizados ou populares), ou campus universitário (ARANTES; VAINER; MARICATO, 2012; HARVEY, 1996).

[...] a competição interurbana e o empresariamento abriram o espaço urbano dos países capitalistas avançados a todos os tipos de novos padrões de empreendimento imobiliário, mesmo que o resultado 'líquido' disto tenha sido a reprodução em série de parques de ciência, da elitização de bairros, de centros de comércio internacional, de centros culturais e de entretenimento e de shopping centers de grande escala com fachadas pós-modernas (HARVEY, 1996, p. 57).

O planejamento estratégico e as políticas estratégicas são uma forma de potencializar as ações municipais de modo a permitir um melhor gerenciamento de eventuais conflitos. Contudo, o seu principal propósito esperado, tanto nas empresas como nas cidades, é a competitividade com fins lucrativos. O tema gera polêmica, pois, para muitos dirigentes políticos e para os empresários, os ganhos são maiores que os riscos a serem enfrentados. Todavia, para a sociedade, que arca com os riscos, essa equação nem sempre tem resultados somente positivos.

\section{A política estratégica do Plano Diretor de Aparecida de Goiânia}

Como outras cidades goianas, Aparecida de Goiânia teve seu início na doação de terras para a construção da Igreja de Nossa Senhora Aparecida (hoje Praça da Matriz, no centro da cidade), no ano de 1922. A partir de então, o vilarejo se formou ao redor da Igreja. Na década de 1950, teve início o processo de parcelamento da cidade, até então distrito de Goiânia. Com a crescente demanda da construção civil de Goiânia por insumos, como saibro, brita e areia, muitas famílias se instalaram nas proximidades de jazidas desses minérios, gerando uma ocupação ainda incipiente do território. Aparecida de Goiânia se emancipou no ano de 1963, década de forte ocupação do território goiano (APARECIDA DE GOIÂNIA, 2001).

O forte movimento migratório sofrido pelo estado de Goiás nos anos de 1960, estimulado principalmente pela construção da BR-153 e de Brasília, fez com que se elaborasse, em 1971, a Lei Municipal de Parcelamento de Goiânia (Lei Municipal $\left.n^{\circ} 4.526 / 1972\right)$, que previa manter o processo de urbanização da capital goiana sob controle, com regras restritivas ao parcelamento. Assim, os agentes imobiliários iniciaram um movimento especulativo nas cidades vizinhas a Goiânia e de modo muito particular em Aparecida de Goiânia. 
Dentro dessa perspectiva, Aparecida teve sua população praticamente dobrada em dez anos, conforme dados do IBGE apresentados no quadro a seguir.

Quadro 1 - População de Aparecida de Goiânia, 1991 a 2010

\begin{tabular}{|c|c|}
\hline Ano & População (hab.) \\
\hline 1991 & 178.483 \\
\hline 1996 & 264.063 \\
\hline 2000 & 336.392 \\
\hline 2007 & 475.303 \\
\hline 2010 & 455.657 \\
\hline
\end{tabular}

Fonte: IBGE, 2011.

Nesse período (décadas de 1970 e 1980) em que Goiânia implantou a Lei de Parcelamento, outras formas de urbanizar a capital foram suplantadas, agora com um parcelamento voltado para as classes mais altas, em locais com infraestrutura já consolidada. Logo, disseminaram-se os loteamentos populares e assentamentos do governo nas cidades limítrofes a Goiânia, em especial em Aparecida de Goiânia.

Contudo, mais veloz e predatório que o processo de ocupação do município foi seu próprio processo de parcelamento, movido pela especulação do mercado imobiliário, que "sofria" as restrições da Lei de Parcelamento de Goiânia. Foram aprovados cerca de 140 loteamentos, 143 desmembramentos e 35 remembramentos entre as décadas de 1970 e 1980. Essas ações resultaram em cerca de 80 mil novos lotes (APARECIDA DE GOIÂNIA, 2002a), gerando uma disponibilidade muito além da realidade local, como ilustra a figura 1.

Figura 1 - Número de famílias x oferta de lotes em Aparecida de Goiânia

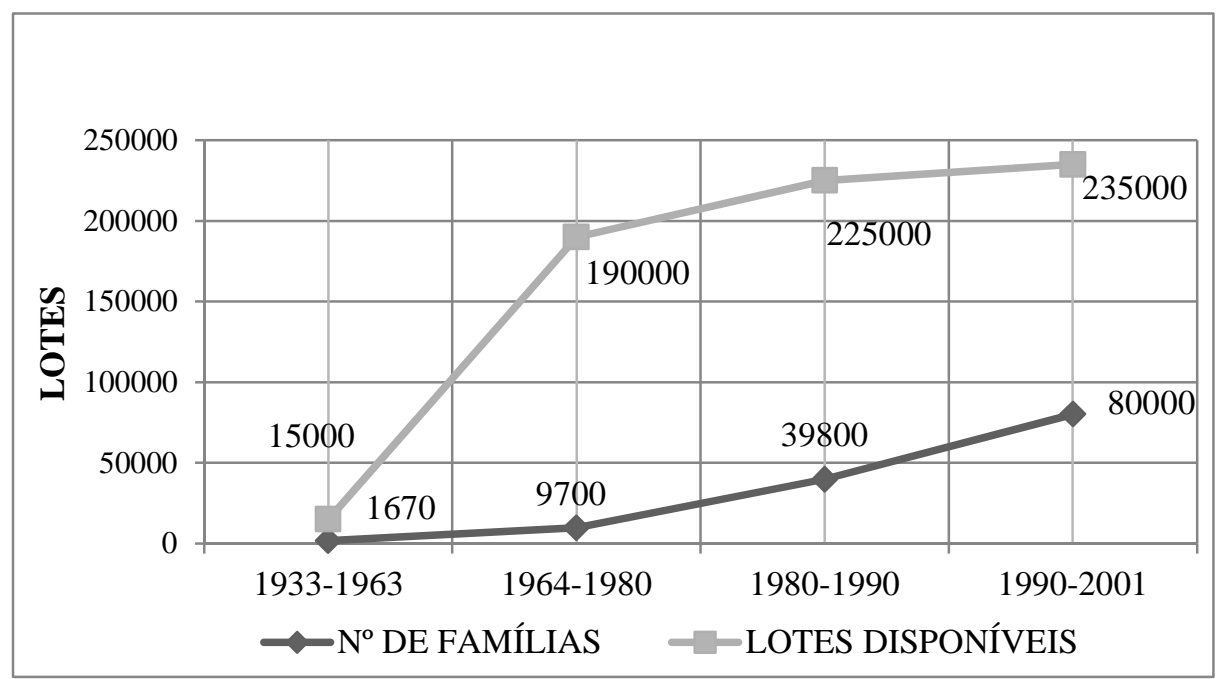

Fonte: PEMAS (APARECIDA DE GOIÂNIA, 2002a). 
Desta forma, Aparecida de Goiânia desenvolveu-se de forma dispersa, com uma malha urbana extensa e desarticulada, com grandes vazios urbanos, além de graves problemas de ligação viária, acessibilidade, infraestrutura e provisão de serviços públicos, fatos que acarretam, até os dias atuais, altos custos com infraestrutura e serviços, considerando que a extensão dos problemas urbanos não é compatível com a disponibilidade de investimentos públicos municipais.

[...] houve uma expansão horizontal extensiva e com densidade rarefeita no município vizinho de Aparecida de Goiânia. Já em meados dos anos 80, praticamente toda a área do município estava parcelada. Estimavase, em 1980, um total de 193.724 lotes criados no município de Aparecida, o que daria para abrigar aproximadamente um milhão de habitantes, população, na época, maior do que aquela existente em Goiânia e sua Região (MORAES, 1991, p. 60).

Enfim, Aparecida de Goiânia desenvolveu-se a partir das leis urbanísticas de Goiânia, tanto com os estudos para o Plano Diretor de Goiânia nos anos 1960, como pela implementação da Lei Municipal de Parcelamento de Goiânia em 1972 (MORAES, 1991). Se essas leis pretendiam conter o impulso da expansão urbana da capital, ao final elas acabaram por permitir uma explosão demográfica e um crescimento do tecido urbano fragmentado de Aparecida de Goiânia, além de incitar a conurbação dos dois municípios.

Aparecida de Goiânia reúne a segunda maior população do Estado, com 455.657 habitantes (censo demográfico IBGE, 2010), fazendo parte da Região Metropolitana de Goiânia (RMG) juntamente com outros 19 municípios: Abadia de Goiás, Aragoiânia, Bela Vista de Goiás, Bonfinópolis, Brazabrantes, Caldazinha, Caturaí, Goianápolis, Goiânia, Goianira, Guapó, Hidrolândia, Inhumas, Nerópolis, Nova Veneza, Santo Antônio de Goiás, Senador Canedo, Terezópolis de Goiás e Trindade ${ }^{3}$.

O cenário urbano de Aparecida de Goiânia pôde ser reconstruído com o seu primeiro plano diretor, que teve início junto a um projeto interinstitucional da prefeitura municipal e do Curso de Especialização em Planejamento Urbano e Ambiental oferecido pela PUC-GO, através da ARCA (Associação para a Recuperação e Conservação do Ambiente), entre os anos de 1998 e 1999. Durante esse curso, Aparecida de Goiânia foi utilizada como "laboratório" de pesquisa urbana e um dos produtos formulados durante a pesquisa foi o diagnóstico que levantou os problemas e as potencialidades da cidade (ARIMATÉA, 2013).

\footnotetext{
${ }^{3}$ A Região Metropolitana de Goiânia foi institucionalizada pela Lei Complementar no 27 , de 30 de dezembro de 1999, alterada pelas Leis Complementares $n^{\circ} 78$, de 25 de março de 2010, e $n^{\circ}$ 87, de 7 de julho de 2011. Fonte: Instituto Mauro Borges - SEGPLAN (GOIÁS, 2013).
} 
A partir dessa experiência e com esforços para requalificar o ambiente urbano, a prefeitura de Aparecida de Goiânia (gestões 1996-2000 e 2000-2004) desencadeou a implantação do Planejamento Municipal Integrado e a implementação de políticas urbanas, como a elaboração do Plano Diretor Municipal. Dando continuidade aos trabalhos já iniciados, a ARCA foi contratada para elaborar o plano diretor de Aparecida de Goiânia, chamado de Plano Diretor Participativo PDP (ARIMATÉA, 2013).

Em maio de 2001, o trabalho foi finalizado. Contudo, as discussões e a proximidade na aprovação do Estatuto da Cidade, que se deu em julho de 2001, fizeram com que a equipe responsável pela elaboração do PDP aguardasse a sanção do Estatuto da Cidade para uma possível adequação. Aprovado o Estatuto da Cidade, a elaboração do PDP foi retomada para se adaptar ao Estatuto. O PDP foi entregue à prefeitura em novembro de 2001 e a lei sancionada em janeiro de 2002 (Lei Complementar $\mathrm{n}^{\circ}$ 004/2002), tornando-se assim o primeiro plano diretor do Estado a seguir os preceitos do Estatuto da Cidade.

O PDP de Aparecida de Goiânia teve como intuito o ordenamento territorial, tentando minimizar os efeitos negativos ocasionados pelo crescimento desordenado pelo qual o município passou e visando impedir que tais impactos ocorressem novamente. Estabeleceu-se, dessa maneira, uma política de expansão urbana de modo a impedir o crescimento urbano especulativo, com degradação do meio ambiente e gastos excessivos com infraestrutura. Procurou-se convergir os investimentos públicos em áreas já adensadas e na reestruturação das principais ligações viárias da cidade, assim como recompor o estoque de áreas públicas, escassas nos primeiros loteamentos do município.

Para isso, segundo informações da equipe elaboradora PDP (APARECIDA DE GOIÂNIA, 2001), o Plano apoiou-se em eixos: i) reestruturação administrativa; ii) combate à exclusão social; iii) retração da malha urbana; iv) reorganização do sistema viário e do de transporte coletivo; v) resgate das áreas públicas; vi) reparação, requalificação e preservação do ambiente natural; vii) distribuição equitativa de equipamentos coletivos públicos; viii) priorização de áreas para ocupação e para investimentos públicos.

Outro eixo importante foi a gestão descentralizada, com as chamadas Regiões Administrativas - RA agrupadas de acordo com características comuns, originadas no seguinte processo: dada a malha urbana desarticulada e dispersa que se encontrava em Aparecida de Goiânia, vários núcleos foram surgindo, independentes uns dos outros, com características e funções próprias, os chamados subcentros. Esses deram origem às chamadas regiões administrativas, que facilitariam a gestão de programas e políticas específicas condizentes com as características de cada região do município. Foram divididas em sete, a saber: Santa Luzia, Centro, Garavelo, Vila Brasília, Tiradentes, Papillon e Cidade Livre (APARECIDA DE GOIÂNIA, 2002b). 
O Plano Diretor apresentado pela equipe de elaboração à administração pública continha: Diagnóstico do Município; Lei das Diretrizes do Plano Diretor; Lei de Política de Ordenação para o Crescimento e Desenvolvimento Estratégico (POCDE); Lei do Perímetro Urbano; Lei do Parcelamento; Lei do Zoneamento (complementada com Código de Obras e Edificações, Código de Posturas, Código de Meio Ambiente e Política Habitacional) (APARECIDA DE GOIÂNIA, 2002b).

Dentre todos os meios legais institucionalizados em Aparecida de Goiânia pelo Plano Diretor Participativo, um chama a atenção - tanto por trazer princípios do planejamento estratégico ou mais precisamente uma política estratégica (algo não habitual nas gestões municipais do estado de Goiás), como por ser extremamente específico às necessidades e realidade do município: a chamada Lei de Política de Ordenação para o Crescimento e Desenvolvimento Estratégico do Município de Aparecida de Goiânia (POCDE) - Lei Municipal no 2.246/2002 (APARECIDA DE GOIÂNIA, 2002c).

A POCDE busca sistematizar a ocupação racional e sustentável do território coordenando as ações municipais de forma integrada, e estabelecendo prioridades de investimentos públicos e otimizando o uso dos recursos para qualificação do ambiente antropizado. Esta política se constitui de um desdobramento das diretrizes do planejamento, em propostas de ações municipais integradas para os temas de parcelamento urbano, uso do solo, habitação, infraestrutura [sic], equipamentos e serviços urbanos e meio ambiente (APARECIDA DE GOIÂNIA, 2002c, p. 4).

Essa lei procurou ordenar o território do município de Aparecida de Goiânia (APARECIDA DE GOIÂNIA, 2001) de forma racional e sustentável, apresentando uma leitura do território urbano da cidade com sua infraestrutura, vazios urbanos e serviços públicos, em que:

- Os efeitos do crescimento desordenado fossem minimizados;

- Houvesse uma ocupação racional e sustentável no território;

- As ações municipais integradas fossem fomentadas e

- As prioridades de investimentos públicos estivessem voltadas para as áreas mais adensadas da cidade.

Esses elementos visavam assegurar que as políticas públicas implementadas a partir de então possibilitassem um desenvolvimento ordenado e um crescimento estratégico do município.

Entretanto, é notório que, como apresentado, esse Planejamento Estratégico não se limitou ao bom ordenamento e ao crescimento estratégico do município, mas 
também visou a transformação da cidade em mercadoria a ser consumida. Tendo em vista a heterogeneidade de aspectos relativos à ocupação territorial e à disponibilidade de serviços urbanos e de infraestrutura que Aparecida de Goiânia apresentava, a Lei de POCDE definiu seis áreas-programas que necessitavam de ações similares por parte da administração municipal, já que essas áreas apresentavam padrões análogos "quanto à ocupação, densidade, infraestrutura [sic] existente, equipamentos e serviços públicos implementados, acessibilidade e paisagem urbana” (APARECIDA DE GOIÂNIA, 2002c, p. 5).

De acordo com a Lei de POCDE (2002c) as áreas-programa são ${ }^{4}$ :

1) Áreas impróprias para ocupação - AIO (grifadas na cor vermelha);

2) Áreas não prioritárias de investimentos públicos - ANIP (grifadas na cor amarela);

3) Áreas prioritárias de ocupação - APO (grifadas na cor azul);

4) Áreas prioritárias para investimentos públicos - APIP (grifadas na cor verde);

5) Áreas para o desenvolvimento estratégico - ADE (grifadas na cor rosa);

6) Áreas para crescimento acompanhado - ACA (grifadas na cor cinza).

A Lei de POCDE (2002c) traz o conceito de cada uma dessas áreas.

Área imprópria para ocupação (AIO) - são áreas que trazem algum risco na sua ocupação ou possuem interesse de preservação ambiental, como áreas de solo frágil propício à erosão, áreas de exploração mineral e áreas de aterro sanitário ou depósito de lixo.

Área não prioritária de investimentos públicos (ANIP) - são áreas cujos loteamentos apresentam baixa ocupação - menos de 10\%, logo uma densidade populacional muito pequena e estão afastadas das áreas mais adensadas e distantes dos serviços públicos e infraestruturas urbanas existentes.

Área prioritária de ocupação (APO) - são aquelas inseridas no perímetro urbano e que já possuem um atendimento de serviços públicos e infraestrutura urbana, mas ainda apresentam lotes vagos passíveis de ocupação.

Área prioritária para investimentos públicos (APIP) - áreas que apresentam um alto índice de densidade populacional, mas ainda carecem de infraestrutura urbana. Área para o desenvolvimento estratégico (ADE) - são aquelas situadas nas adjacências das áreas centrais ou adensadas e ainda não loteadas e carentes de áreas públicas.

Área para crescimento acompanhado (ACA) - áreas já parceladas com ocupação total ou parcial, mas não incorporadas a programas específicos.

\footnotetext{
${ }^{4}$ Cada área foi grifada com uma cor para que, desse modo, fosse possível o mapeamento e, consequentemente, a melhor visualização das áreas.
} 
Seguindo, ainda, os conceitos das áreas-programas da POCDE e traçando-se um paralelo com as fases de elaboração e implementação do Planejamento Estratégico que Oliveira (2010) apresenta - Fase I, diagnóstico estratégico; Fase II, missão da empresa; Fase III, instrumentos prescritivos e quantitativos; e Fase IV, controle e avaliação -, podem se observar as ações e estratégias da POCDE de Aparecida de Goiânia.

$\mathrm{Na}$ Fase I (diagnóstico estratégico) são analisados e verificados "os aspectos inerentes à realidade externa e interna da empresa". É a hora em que se determina "como se está" (OLIVEIRA, 2010, p. 43). Pode-se afirmar que essa fase foi cumprida pelo Planejamento Estratégico de Aparecida de Goiânia, com o Diagnóstico do Município realizado durante a elaboração do PDP, quando tanto os aspectos internos da prefeitura como a realidade municipal foram levantados e, desse modo, estabelecido como a cidade se encontrava.

Na Fase II (missão da empresa) deve-se apresentar "a razão de ser da empresa, bem como seu posicionamento estratégico" (OLIVEIRA, 2010, p. 50). Para o PDP de Aparecida de Goiânia e especificamente para a Lei de POCDE, a missão do município era regular seu crescimento territorial, o que fica claro na descrição da própria Lei: “a POCDE busca sistematizar a ocupação racional e sustentável do território [...] otimizando o uso dos recursos para qualificação do ambiente antropizado." (APARECIDA DE GOIÂNIA, 2002c, p. 4).

Durante a Fase III (instrumentos prescritivos e quantitativos), a questão básica é situar "onde se quer chegar" e "como chegar na situação desejada" (OLIVEIRA, 2010, p. 52). Para o cumprimento dessa fase, a Lei de POCDE estabeleceu suas seis áreas-programa, que traziam, além dos seus objetivos e conceitos, como apresentado, os instrumentos possíveis para se aplicar a Lei, ou seja, "como se chegar à situação desejada".

A Fase IV (controle e avaliação), ainda de acordo com Oliveira (2010), é a etapa em que se verifica "como a empresa [município] está indo" para alcançar a posição desejada. Nessa fase, verifica-se uma falha na Lei de POCDE e, principalmente, nas políticas estratégicas municipais, o que acontece com vários instrumentos de planejamento urbano em todo o país: a falta de controle e avaliação.

A Lei de POCDE, apesar de trazer os instrumentos que poderiam operacionalizála, na verdade foi constituída de "diretrizes, objetivos, conceitos etc. - que não obrigam ninguém a fazer ou deixar de fazer nada" (VILLAÇA, 2005, p. 23). Não define, por exemplo, qual a obrigação e de qual órgão municipal seria seu cumprimento e avaliação.

Todavia, salienta-se a importância da elaboração do PDP de Aparecida de Goiânia e da sua política estratégica - Lei de POCDE, uma vez que a reconstrução urbana do município só foi possível e validada a partir da elaboração de tais instrumentos legais. 


\section{Considerações finais}

Conformar as necessidades municipais, a participação popular e a liberdade de elaboração são os ganhos e desafios em se combinar os dois tipos de planos apresentados - PDM e PEM. Percebe-se a importância dessa articulação por serem esses dois instrumentos similares e complementares na gestão municipal. A simples elaboração dos planos e políticas municipais já é um grande ganho para o município, mesmo sem considerar seus resultados. O desafio é o monitoramento dos planos, a exigência na continuidade, fiscalização e (re)avaliações, pois nem os planos diretores que possuem essa prática pelo governo federal são realmente efetivos.

No caso de Aparecida de Goiânia, os instrumentos implementados pelo Plano Diretor Participativo de 2001, especificamente pela Lei de POCDE, contribuíram para a redução do processo desordenado de ocupação do solo, auxiliando a reestruturação da malha urbana. Mas a prática da gestão pública que permeia as prefeituras do país também é verificada na cidade:

- Com ações emergenciais para "apagar o fogo", enquanto o planejamento é visto e feito apenas como etapa a ser cumprida por obrigação legal;

- Com corpo técnico pequeno e sem especialização para implementar os instrumentos de planejamento urbano;

- Pela falta de controle e averiguação das etapas do planejamento; e

- Com um planejamento urbano com vistas à especulação imobiliária, que desvenda a cidade como um grande campo de investimentos.

Apesar de a política estratégica e do Plano Diretor de Aparecida de Goiânia terem possibilitado a reconstrução da malha urbana da cidade, não se pode negar que eles foram elaborados em um período em que o planejamento urbano brasileiro já havia incorporado questões do empresariamento urbano.

Um exemplo deste empresariamento urbano em Aparecida de Goiânia é a localização do Polo Empresarial Goiás, o maior do município e um dos maiores do estado. Este Polo foi lançado em 1997 com a desapropriação de 100 alqueires $\left(4.840 .000 \mathrm{~m}^{2}\right)$; em 2002, foi realizada uma expansão de mais $51.000 \mathrm{~m}^{2}$. Um trecho do Polo Empresarial Goiás fica em uma área tratada pela POCDE como área para desenvolvimento estratégico (ADE), ou seja, área localizada nas imediações de áreas centrais ou já adensadas que ainda não foram loteadas e são carentes de áreas públicas. O Polo Empresarial é, pois, uma área interessante para empresas se instalarem haja visto a facilidade de acesso (localiza-se às margens da BR-153), a proximidade com o centro da cidade e com áreas já ocupadas.

O mais pertinente para se instalar nessas áreas, no entanto, dentro dos parâmetros do urbanismo como instrumento social, seriam habitações pelos mesmos motivos 
apresentados. As empresas que se instalaram no Polo e as que vierem a se instalar recebem uma cessão da área (LAURIA; MOISÉS; PASQUALETTO, 2012). Não pagam nada para se alojar em áreas tão especiais da cidade, mesmo de uma cidade que sofreu e sofre com a malha urbana dispersa devido a loteamentos abertos sem ligação com os já ocupados. Na própria Lei de POCDE, as áreas para o desenvolvimento estratégico são descritas como áreas carentes de áreas públicas. Com a instalação das empresas, esse fato continua presente e reafirma a ideia de que os interesses do mercado se sobressaem aos interesses públicos.

Assim, como não perceber a ação do mercado na formulação de leis e outros arranjos legais capazes de transformar a cidade em uma grande mercadoria?

\section{Referências}

APARECIDA DE GOIÂNIA. Seminário Participativo: Plano Diretor 20012010 - Planejando no Presente o Futuro da Cidade. Aparecida de Goiânia, 2001.

- Relatório Final do município de Aparecida de Goiânia ao programa Habitar Brasil do Banco Interamericano de Desenvolvimento, de abril de 2002. Plano Estratégico Municipal para Assentamentos Subnormais (PEMAS). Aparecida de Goiânia, 2002a. (Inédito).

- Lei Complementar $\mathrm{n}^{\mathrm{o}}$ 004/2002, de 30 de janeiro de 2002. Planejamento Municipal Sustentável, o Plano Diretor do Município de Aparecida de Goiânia. Aparecida de Goiânia, 2002b.

Lei Municipal no 2.246/2002, de 30 de janeiro de 2002. Política de Ordenação para o Crescimento e Desenvolvimento Estratégico (POCDE) do Município de Aparecida de Goiânia. Aparecida de Goiânia, 2002c.

ARANTES, Otília; VAINER, Carlos; MARICATO, Ermínia. A cidade do pensamento único: desmanchando consensos. 7. ed. Petrópolis, RJ: Vozes, 2012.

ARIMATÉA, Marcos Aurélio Lopes de. Entrevista. Entrevistadora: Lorena S. Assunção. Goiânia, abril de 2013. Digital Music Player (23 min).

ARRETCHE, Marta T. da Silva. Emergência e Desenvolvimento do Welfare State: Teorias Explicativas. BIB Revista Brasileira de Informação Bibliográfica em Ciências Sociais. Rio de Janeiro, v. 39, p. 3-40, 1995. Disponível em: <http://xa.yimg.com/kq/groups/25228238/608444617/name/ Arretche_1996_BIB.pdf $>$. Acesso em: 11 jun. 2012. 
BORJA, Jordi; FORN Manuel de. Políticas da Europa e dos Estados para as cidades. Espaço \& Debates. São Paulo, ano XVI, n. 39, p. 32-47, 1996.

BRASIL. Constituição da República Federativa do Brasil, de 5 de outubro de 1988. Brasília, 1988. Disponível em: <http://www.planalto.gov.br/ ccivil_03/constituicao/constitui\%C3\%A7ao.htm>. Acesso em: 20 ago. 2012.

Lei Federal no 10.257/2001, de 10 de julho de 2001. Estatuto da Cidade. Brasília, 2001. Disponível em: <http://www.presidencia.gov. br/ccivil_03/LEIS/LEIS2001/L10257.htm>. Acesso em: 1 nov. 2011.

CARDOSO, Fábio Luiz Lopes. A influência do relatório beveridge nas origens do welfare state (1942 - 1950). Artigo de Pesquisa de Iniciação Científica. FCLAR/UNESP, Araraquara, SP, [2010?]. Disponível em: <http://www.sinteseeventos.com.br/bien/pt/papers/fabioluizlopesainfluenciado relatoriobeveridge.pdf $>$. Acesso em: 1 jun. 2012.

CORREAA, Roberto Lobato. O Espaço Urbano. 3. ed. São Paulo: Ática, 1995.

DEL RIO, Vicente. Introdução ao desenho urbano no processo de planejamento. São Paulo: Pini, 1990.

DROUIN, Jean-Claude. John Maynard Keynes, Reformador do Capitalismo. In: DROUIN, Jean-Claude. Os Grandes Economistas. Tradução Denise Bottmann. 1. ed. São Paulo: Martins, 2008. cap. 7, p. 113-136.

GOIÁS, Governo de. Instituto Mauro Borges. Secretaria de Estado de Gestão e Planejamento. Disponível em: <http://www.imb.go.gov.br>. Acesso em: 10 de junho de 2013.

GRUPPI, Luciano. A Concepção do Estado em Lênin e Gramsci. In: GRUPPI, Luciano. Tudo Começou com Maquiavel - As concepções de Estado em Marx, Engels, Lênin e Gramsci. 12 ed. Porto Alegre: L\&PM, 1980. parte II, p. 47-92.

HARVEY, David. Do gerenciamento ao empresariamento: a transformação da administração urbana no capitalismo tardio. Espaço \& Debates. São Paulo, ano XVI, n. 39, p. 48-64, 1996.

. Entrevista As Cidades Rebeldes de David Harvey. Entrevistadores: John Brissenden e Ed Lewis. Tradução: Daniela Frabasile e Laís Bellini. New Left Project. 13 de julho de 2012. Disponível em: <http://www.outraspalavras. net/2012/07/13/as-cidades-rebeldes-de-david-harvey $>$. Acesso em: 7 out. 2012. 
IBGE. Cidades@ Disponível em: <http://www.ibge.gov.br/ cidadesat/topwindow.htm?1>. Acesso em: 20 out. 2011.

LAURIA, Ivna O; MOISÉS, Aristides; PASQUALETTO, Antonio. Distritos empresariais como agentes de desenvolvimento regional em áreas públicas em Aparecida de Goiânia. Estudos. Goiânia, v. 39, n. 1, p. 61-71, jan-mar 2012. Disponível em: <http://seer.ucg.br/index.php/estudos/article/view/2365/ 1454>. Acesso em: 13 nov. 2013.

MARICATO, Ermínia. Metrópole, legislação e desigualdade. Estudos Avançados, São Paulo, v. 17, n. 48, p. 151-166, mai-ago 2003. Disponível em: <http://www.scielo.br/pdf/ea/v17n48/v17n48a13.pdf>. Acesso em: 16 ago. 2012.

MORAES, Sérgio de. O Empreendedor Imobiliário e o Estado: o Processo de Expansão de Goiânia em Direção Sul (1975-1985). 1991. 129 f. Dissertação de Mestrado. Instituto de Arquitetura e Urbanismo - Departamento de Urbanismo, UnB, Brasília, 1991.

OLIVEIRA, Djalma de Pinho Rebouças de. Planejamento estratégico: conceitos, metodologia e práticas. 28. ed. São Paulo: Atlas, 2010.

PFEIFFER, Peter. Planejamento estratégico municipal no Brasil: uma nova abordagem. Texto para discussão - ENAP. Brasília, n. 37, out. 2000. Disponível em: <http://www.enap.gov.br/index.php?option=com_docman\& task=doc_download\&gid=1641>. Acesso em: 25 abr. 2013.

REZENDE, Denis Alcides. Modelos de Integração no Planejamento Municipal: Descrição da Experiência de um Município Paranaense. Revista Eletrônica de Gestão Organizacional. Pernambuco, v. 4, n. 2, p. 194-212, mai./ago. 2006. Disponível em: <http://www.revista.ufpe.br/gestaoorg/index.php/gestao/ article/viewFile/84/75>. Acesso em: 25 abr. 2013.

REZENDE, Denis Alcides; ULTRAMARI, Clovis. Plano diretor e planejamento estratégico municipal: introdução teórico-conceitual. Rio de Janeiro: RAP, mar/abr 2007. Disponível em: <http://www.scielo.br/ pdf/rap/v41n2/05.pdf>. Acesso em: 23 ago. 2012. 
RODRIGUES, Fabiana de Cássia. O papel da questão agrária no desenvolvimento do capitalismo nacional, entre 1954 e 1964 em Caio Prado Junior, Celso Furtado, Ignácio Rangel e outros autores pecebistas. Dissertação de Mestrado. UNICAMP, Campinas, 2005. Disponível em: $<$ http://www.bibliotecadigital.unicamp.br/document/?code=vtls000377296\&opt =4>. Acesso em: 3 mai. 2012.

ROLNIK, Raquel; PINHEIRO, Otilie Macedo. Plano diretor participativo: guia para elaboração pelos municípios e cidadãos. 2. ed. Brasília: Confea, 2005.

SANTOS, Milton. A Urbanização Brasileira. São Paulo: HUCITEC, 1993.

. O Dinheiro e o Território. GEOgraphia. Niterói, RJ, v.1, n. 1, p. 7-13, set. 1999. Disponível em: <http://www.uff.br/geographia/ojs/index.php/ geographia/article/view/2>. Acesso em: 29 mai. 2013.

SANTOS JUNIOR, Orlando Alves dos; MONTANDON, Daniel Todtmann (orgs.). Os planos diretores municipais pós-estatuto da cidade: balanço crítico e perspectivas. Rio de Janeiro: Letra Capital, 2011.

VILLAÇA, Flávio. As ilusões do plano diretor. 1 ed. São Paulo: Edição do autor, 2005. Disponível em: <http://www.flaviovillaca.arq.br/>. Acesso em: 12 set. 2011. (Divulgado apenas pela Internet).

2012.

. Reflexões Sobre as Cidades Brasileiras. São Paulo: Studio Nobel,

Endereço para correspondência:

Deusa Maria Rodrigues Boaventura -dmrb@terra.com.br

Av. Universitária, 1.440, Setor Universitário

74605-010 Goiânia/GO, Brasil

Lorena Sulino Assunção - losulino@hotmail.com

$5^{a}$ Avenida, s/n, área I, Bloco B, Setor Universitário

76605-020 Goiânia/GO, Brasil 